\title{
Discrete spawning aggregations of loliginid squid do not represent genetically distinct populations
}

\author{
P. W. Shaw ${ }^{1, *}$, L. Hendrickson ${ }^{2}$, N. J. McKeown ${ }^{1}$, T. Stonier ${ }^{3}$, M.-J. Naud ${ }^{1,4}$, \\ W. H. H. Sauer ${ }^{3}$ \\ ${ }^{1}$ School of Biological Sciences, Royal Holloway University of London, Egham TW20 0EX, UK \\ ${ }^{2}$ US National Marine Fisheries Service, Northeast Fisheries Science Center, 166 Water St., Woods Hole, \\ Massachusetts 02543, USA \\ ${ }^{3}$ Department of Ichthyology \& Fisheries Science, Rhodes University, Grahamstown, South Africa \\ ${ }^{4}$ Present address: Marine Biological Association of the UK, Citadel Hill, Plymouth, Devon PL1 2PB, UK
}

\begin{abstract}
Establishing whether heavily fished spawning aggregations of squid represent genetically distinct populations is important for fisheries management, especially in light of recent efforts to apply ecosystem-based management methods and the importance of squid as both predator and prey. Most squid species have the potential for high dispersal rates due to lengthy planktonic paralarval stages and highly migratory adult stages. Such life-history traits lead to predictions of genetic homogeneity (i.e. panmixia) of squid populations across large geographical areas. However, testing this hypothesis can be difficult, because spawning populations of squid are highly mobile and spawning sites are either unknown or spread sparsely over large geographical areas. Loligo reynaudii and Doryteuthis (Amerigo) pealeii are 2 squid species that are commercially fished on inshore spawning grounds located off the coasts of South Africa and the eastern USA, respectively, and for which highly localised spawning aggregations have been documented. We sampled discrete spawning aggregations of these 2 neritic species, so that the highest likelihood of sampling true reproductive populations was achieved, in order to determine whether such spawning aggregations represent discrete genetic populations. As has been reported for many squid species, the levels of genetic diversity detected at nuclear microsatellite DNA loci, within both $L$. reynaudii and D. pealeii, were high and consistent across all samples. Our results for $D$. pealeii indicated that adjustments of allele frequencies using MicROCHECKER to take the presence of null alleles into account may introduce bias, due to the presence of loci with small numbers of common alleles; this leads to a conclusion that there is significant genetic differentiation among populations where none exists. For both species, our results indicated no significant genetic differentiation of populations and, thus, no association of spawning aggregations with distinct genetic subpopulations, across the main spawning ranges sampled.
\end{abstract}

KEY WORDS: Loligo sp. - Doryteuthis sp. - Squid population genetics - Spawning aggregations · Panmixia $\cdot$ Microsatellite DNA $\cdot$ MicrocheCKER $\cdot$ Null alleles

\section{INTRODUCTION}

An intuitive assumption regarding population structuring in marine organisms is that species with highly mobile adults and/or planktonic larval stages have high dispersal potential and will display panmixia (i.e. interbreeding leading to little or no structuring) over large distances. Molecular markers have proved useful for testing genetic structuring, and, although widespread panmixia has been confirmed in many species (Avise 2004), a growing number of cases in both marine vertebrates (e.g. cod: Ruzzante et al. 2001, herring: Mariani et al. 2005) and invertebrates (e.g. cuttlefish: Perez Losada et al. 2002, lobsters: Triantafyllidis 
et al. 2005, crabs: Sotelo et al. 2008) have demonstrated that the dispersal and interbreeding realised is often much lower than the levels predicted from life-history characteristics (Palumbi 2004). Although the degree of genetic structuring of marine species is usually much lower than that reported for freshwater or terrestrial species, the biological significance of low levels of genetic structure has been supported by correlation of population differentiation with environmental factors (Bekkevold et al. 2005) or by temporal and spatial replication (Cimmaruta et al. 2008). Understanding genetic substructuring of marine species is important for understanding how populations evolve, for example in response to changing environments, and also for stock identification and the evaluation of the selective effects of fisheries on the population structure and life-history traits of managed species.

Squid epitomise marine species with high dispersal potential. Life-history characteristics of most squid species are predicted to result in widespread gene flow because of the highly mobile adult stage - when individuals are known to undertake migrations of 100 s to 1000s of kilometres - and the long-distance transport of planktonic paralarval stages lasting several weeks (Boyle \& Rodhouse 2005). Together with very large census populations that may fluctuate by orders of magnitude across years (Boyle \& Boletzky 1996), the potential for high dispersal leads to predictions of genetic homogeneity (i.e. panmixia) of squid populations. Most studies of squid have supported this prediction and indicated little, if any, genetic structuring over geographical distances of 100 s to 1000 s of kilometres despite important life-history differences between ommastrephid and loliginid squid species (e.g. Adcock et al. 1999, Triantafillos et al. 2004, Dillane et al. 2005, Martínez et al. 2005). Ommastrephid species inhabit deeper shelf and slope waters contiguous with major ocean current systems that aid in the transport of the species' pelagic egg masses and paralarvae (Rodhouse et al. 1998). Consequently, large-scale oceanographic features such as fronts and coastal upwelling cells influence the structuring of ommastrephid populations (Dawe et al. 2007). In contrast, squid species of the family Loliginidae have a sessile benthic egg stage and tend to be neritic in habit, with seasonal distributions that shift between shallow coastal waters and deeper offshore waters along continental shelves. As a result, loliginid populations tend to be physically structured by shallow water topography and seasonal variations in water temperature (Brodziak \& Hendrickson 1999), which affect embryonic development and growth rates and thus determine the amount of exposure time that these early life-history stages are subject to intense predation (Dawe et al. 2007). Even so, most studies of loliginid species have also described genetic homo- geneity of populations over large areas (e.g. Yeatman \& Benzie 1994, Shaw et al. 1999, Reichow \& Smith 2001, Triantafillos \& Adams 2001, Herke \& Foltz 2002, Shaw et al. 2004). One study, however, of Loligo pealeii Lesueur, 1821 along the eastern coast of North America, which specifically targeted sampling of squid in discrete spawning aggregations, has described significant genetic differentiation among locations during the summer spawning season (Buresch et al. 2006).

A true reflection of the breakdown of interbreeding between demes, exhibited as genetic differentiation between populations, will be gained only if adults are sampled during their reproductive phase (i.e. at spawning time on the spawning grounds). For example, Nesbø et al. (2000) detected population structure among samples of Atlantic mackerel Scomber scombrus collected at spawning times, but not among samples collected outside of spawning times. Although efforts are made to sample breeding adults at spawning time in areas where eggs and larvae have been recorded (i.e. putative spawning grounds), most species of squid are difficult to observe in the act of spawning, and accurate locations of breeding sites are unknown for many species. Due to protracted spawning seasons, the facility of individuals (at least among loliginids) to spawn over extended periods (Boyle \& Rodhouse 2005) and the high mobility of adults, it is possible that sexually mature squid in one area at one time may be a mixture from multiple spawning populations. Some studies of squid have determined low levels of genetic differentiation within specific regions or time periods (Carvalho et al. 1992, Martínez et al. 2005), which may indicate greater underlying structuring of populations, possibly resulting from isolated spawning subpopulations within regions.

Our investigation began as a test for genetic differentiation among local spawning aggregations of Loligo reynaudii Orbigny, 1845, a species for which individuals can be sampled from known spawning sites during spawning, as a comparison to the earlier study of $L$. pealeii by Buresch et al. (2006). However, during the course of the study we were asked by staff from the US National Marine Fisheries Service to resample the spawning populations of $L$. pealeii; because initial results for $L$. reynaudii indicated no distinct genetic differentiation of spawning aggregations, we accepted this offer as an opportunity to directly compare results for the 2 species.

Loligo reynaudii is a neritic species distributed around the southwest and southeast coasts of South Africa (Augustyn et al. 1992). Mature adults form spawning aggregations, depositing sessile egg strings on the seabed in highly localised patches. It is postulated that $L$. reynaudii spawn and hatch in inshore waters along the southeast coast of South Africa, 
migrate offshore and westwards to feed and mature, and then return to the spawning grounds to complete their life cycle (Augustyn et al. 1992, 1994, Sauer et al. 1992, Olyott et al. 2007). The main inshore spawning sites are concentrated along the Eastern Cape coast from Tsitsikamma to Port Alfred (see Fig. 1A). Females are serial spawners (Melo \& Sauer 1999), which, together with tagging data that show individuals can move to other spawning sites up to $207 \mathrm{~km}$ away in $18 \mathrm{~d}$ (Sauer et al. 2000), suggests the facility to move between and breed in multiple spawning areas. From what is known of the species' biology, migration patterns and the lack of obvious geographic and hydrographic barriers to movement along this coastline, the null hypothesis prediction is for extensive interbreeding and a single genetic population over a wide area, at least within the main spawning area on the southeast coast.

Loligo pealeii has recently been reclassified as Doryteuthis (Amerigo) pealeii, based on Vecchione et al. (2005), and the species will be referred to hereafter as $D$. pealeii. $D$. pealeii is also a neritic species with a sessile, benthic egg stage and is distributed widely in the northwest Atlantic Ocean and Caribbean Sea (Roper et al. 1984). The main centre of abundance, however, is off the east coast of the USA, between Cape Cod (Massachusetts) and Cape Hatteras (North Carolina; see Fig. 1B), where the species is fished with bottom trawls throughout the year. The lifespan is from $\sim 6$ to $9 \mathrm{mo}$, and spawning occurs year-round, with peaks during winter and summer (Brodziak \& Macy 1996, Macy \& Brodziak 2001). Incidental catches of benthic egg masses by the squid fishery, as well as seasonal sexual maturity patterns (Macy \& Brodziak 2001), have been used to identify inshore and offshore spawning areas located between Cape Cod and Cape Hatteras (Hatfield \& Cadrin 2002). Individuals undergo extensive seasonal migrations of 100 s of kilometres: north of Cape Hatteras, squid migrate offshore and southward during late autumn to overwinter then return inshore during late spring, where they remain until late autumn (Summers 1983, Macy \& Brodziak 2001). Similar to L. reynaudii, the prediction from life-history and migration patterns of $D$. pealeii is for extensive inter-
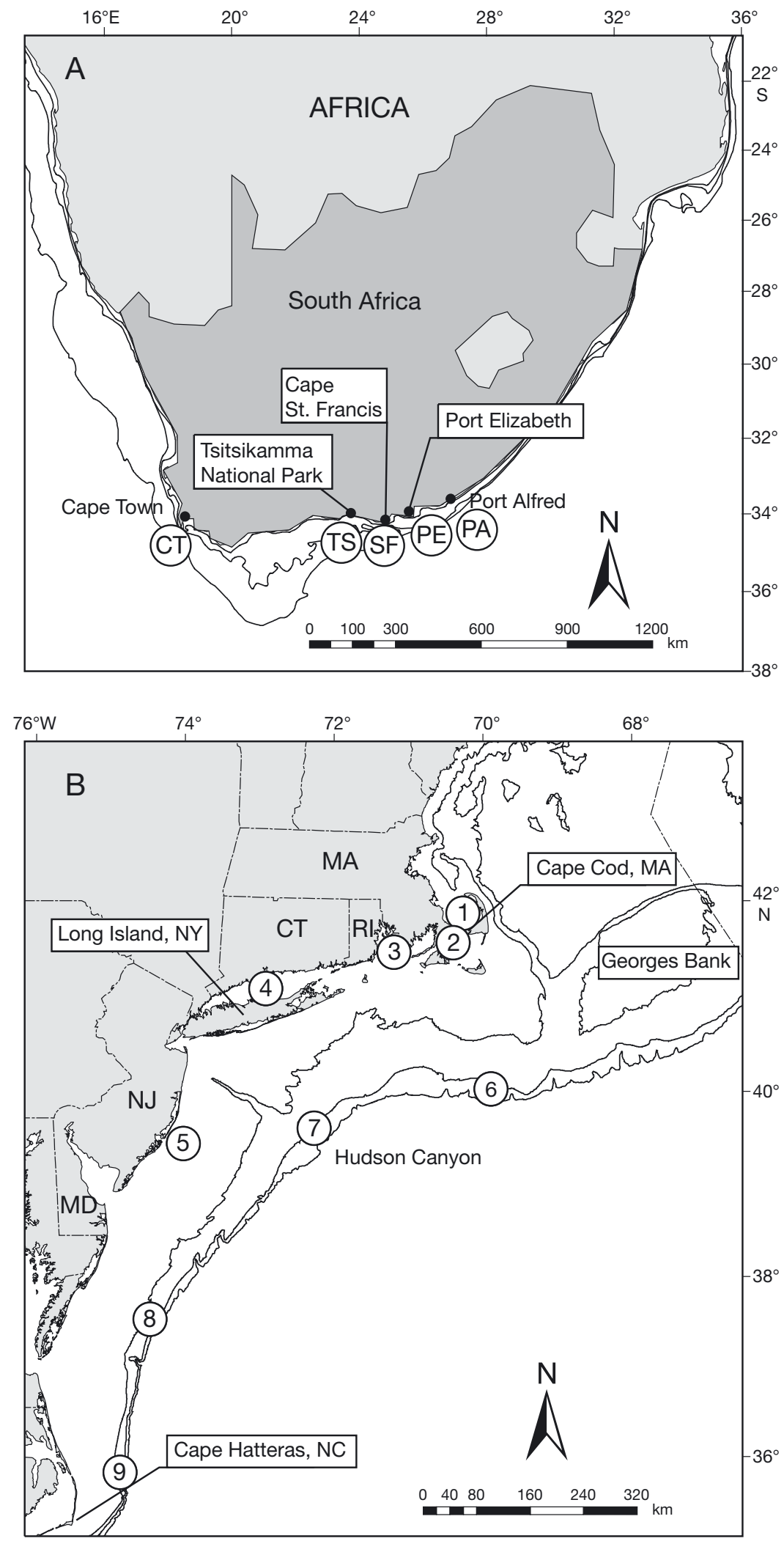

Fig. 1. Sampling locations for (A) Loglio reynaudii around South Africa, and (B) Dorytheuthis paeleii along the eastern coast of the USA. Isobaths 60, 120 and $400 \mathrm{~m}$ are shown. Sample codes for stations are encircled (see Table 1) 
breeding and a single genetic population over large areas along the eastern US coast, a prediction supported in genetic studies by Herke \& Foltz (2002) and Garthwaite et al. (1989). Garthwaite et al. (1989) suggested low levels of genetic differentiation at regional scales along the US east coast (i.e. offshore, on Georges Bank; and inshore, off eastern Cape Cod and Virginia), although they also acknowledged the limited power of the single polymorphic allozyme locus used. Additionally, the Garthwaite et al. (1989) study was conducted during the fall migration period rather than on the spawning grounds. Herke \& Foltz (2002) found no evidence of population substructuring across a geographic range extending further north (southern Scotian Shelf) and south (east coast of Florida) of the area sampled by Garthwaite et al. (1989). In contrast, Buresch et al. (2006) suggested that 4 inshore summer spawning aggregations between Cape Cod (Massachusetts) and Delaware were genetically distinct.

Our study tested the hypothesis that geographically localised spawning aggregations of Loligo reynaudii and Doryteuthis pealeii represent genetically distinct populations. Both squid species, although from different parts of the world, share similar life-history characteristics in terms of inshore migrations of mature adults to form discrete spawning aggregations in shallow coastal waters, where they are the targets of commercial fisheries.

\section{MATERIALS AND METHODS}

Sampling. A key aspect of the present study was to sample squid populations during spawning, so that the highest likelihood of identifying reproductively iso- lated populations was achieved. Loligo reynaudii and Doryteuthis pealeii are 2 of very few squid species for which highly localised spawning aggregations have been documented. In both species spawning takes place in the same approximate geographical locations year after year.

For Loligo reynaudii, inshore spawning aggregations were sampled from commercial jig fishery boats, which locate the spawning aggregations and egg beds using sonar. Four aggregations were sampled in the period from April to June 2006 along the Eastern Cape coast of South Africa in the vicinity of Port Alfred (PA), Port Elizabeth (PE), St Francis Bay (SF06) and the Tsitsikamma National Park Marine Protected Area (TS), plus a sample of spawning squid taken by demersal trawl (late January 2006) on the deeper spawning grounds $(185 \mathrm{~m})$ of the Agulhas Bank south of Cape Town (CT) in the Western Cape region (see Table 1 and Fig. 1A), a geographical range of $\sim 800 \mathrm{~km}$. A sample taken from the spawning aggregation in St Francis Bay in 2003 (SF03) was also included as a test of temporal stability of allele frequencies.

Doryteuthis pealeii samples were collected at 9 sites located throughout the latitudinal range of the species' core habitat along the east coast of the USA between Cape Cod and Cape Hatteras. Individuals were collected during stratified random bottom trawl surveys conducted by the Northeast Fisheries Science Center (Azarovitz 1981) and during state research bottom trawl surveys. Squid were also collected from inshore weirs during the spring spawning period. Squid were collected during summer and winter and presumed to represent both of the primary cohorts: winter-hatched squid (November to May) and summer-hatched squid (June to October), respectively (Brodziak \& Macy

Table 1. Loligo reynaudii and Doryteuthis pealeii. Sample details

\begin{tabular}{|c|c|c|c|c|c|}
\hline Sample code & $\begin{array}{c}\text { Date } \\
(\mathrm{dd} / \mathrm{mm} / \mathrm{yy})\end{array}$ & Location & Sample size & Depth (m) & Sampling method \\
\hline \multicolumn{6}{|l|}{ L. reynaudii } \\
\hline $\mathrm{CT}$ & 28/01/06 & Cape Town (W. Agulhas) & 48 & 185 & Bottom trawl \\
\hline TS & 01/04/06 & Tsitsikamma & 60 & 39 & Jigging \\
\hline SF03 & 05/11/03 & St Francis Bay & 80 & 24 & Jigging \\
\hline SF06 & 16/04/06 & St Francis Bay & 67 & 22 & Jigging \\
\hline $\mathrm{PE}$ & 07/05/06 & Port Elizabeth & 48 & 35 & Jigging \\
\hline $\mathrm{PA}$ & 02/06/06 & Port Alfred & 84 & 37 & Jigging \\
\hline \multicolumn{6}{|l|}{ D. pealeii } \\
\hline 1 & 16/09/06 & Cape Cod Bay, MA & 76 & 30 & Bottom trawl \\
\hline 2 & 05/05/06 & Nantucket Sound, MA & 40 & 6 & Weir \\
\hline 3 & 19/05/06 & Sakonnet Point, RI & 80 & 18 & Weir \\
\hline 4 & $31 / 05 / 06$ & Long Island Sound, CT & 80 & 29 & Bottom trawl \\
\hline 5 & 11/06/06 & Atlantic City, NJ & 80 & 27 & Bottom trawl \\
\hline 6 & $28 / 02 / 07$ & Veatch Canyon & 80 & 144 & Bottom trawl \\
\hline 7 & $22 / 02 / 07$ & Hudson Canyon & 80 & 117 & Bottom trawl \\
\hline 8 & 09/02/07 & Washington Canyon & 80 & 77 & Bottom trawl \\
\hline 9 & $11 / 02 / 07$ & N. of Cape Hatteras, NC & 80 & 108 & Bottom trawl \\
\hline
\end{tabular}


1996). Winter-hatched squid were collected in 2006 at 5 inshore locations (Stns 1 to 5) during the period from May to September, when the species was spawning inshore. Squid hatched primarily during the summer of 2006 were collected in February of 2007 at 4 stations (Stns 6 to 9) located offshore, where the species spends the winter (Table 1, Fig. 1B).

Microsatellite screening. Levels of genetic diversity within and between samples of Loligo reynaudii were assessed using 6 microsatellite loci: Lrey21, Lrey34, Lrey44 and Lrey48 isolated from L. reynaudii (Naud \& Shaw 2008), plus 2 loci isolated from another loliginid (Loligo forbesi), Lfor1 and Lfor3 (Shaw 1997). Samples of Doryteuthis pealeii were assessed using 5 microsatellite loci: Lp2, Lp4, Lp5 and Lp12 isolated from D. pealeii (Maxwell et al. 2000) and Lfor3 (Shaw 1997).

For samples of both species total DNA was extracted from 95\% ethanol-preserved tissue using a CTAB chloroform/IAA method (Winnepenninckx et al. 1993). Microsatellites were amplified using polymerase chain reactions (PCR) performed under the following conditions: $120 \mathrm{~s}$ at $94^{\circ} \mathrm{C}$, then 30 cycles of $30 \mathrm{~s}$ at $92^{\circ} \mathrm{C}, 30 \mathrm{~s}$ at the specific annealing temperature (Shaw 1997, Maxwell et al. 2000, Naud \& Shaw 2008) and $10 \mathrm{~s}$ at $72^{\circ} \mathrm{C}$, using a PTC-200 thermal cycler (MJ Research). Reaction mixes contained $20 \mathrm{ng}$ template DNA, 1.5 to $2.5 \mathrm{mM} \mathrm{MgCl}, 0.2 \mathrm{mM}$ of each nucleotide, $0.2 \mu \mathrm{M}$ of each primer (forward primer $5^{\prime}$ end-labelled with a Cy5 fluorescent dye group), 0.2 U Taq polymerase (Bioline UK) with the manufacturer-supplied $1 \times$ buffer: $160 \mathrm{mM}\left(\mathrm{NH}_{4}\right)_{2} \mathrm{SO}_{4}, 670 \mathrm{mM}$ Tris- $\mathrm{HCl}_{\text {; }}$ in a final reaction volume of $10 \mu \mathrm{l}$. Amplified products were resolved on $6 \%$ denaturing polyacrylamide gels run on an ALFexpressII (Pharmacia Biotech) automated sequencer. Product sizes were determined against internal standard size markers using Fragment Manager v. 1.2 (Pharmacia Biotech) and confirmed against known individual genotypes run across gels. Consistency of PCR amplification and scoring were checked for 2 batches of 40 individuals for each species using new DNA extractions, 2 sets of amplifications and running/scoring each set twice.

Genetic data analysis. Genotypes at all pairs of loci were tested for genotypic linkage disequilibrium and within loci within samples for deviation from HardyWeinberg outcrossing expectations, using exact tests with significance determined by a Markov chain method (Genepop v. 3.3; Raymond \& Rousset 1995). Levels of genetic diversity within samples were estimated as the proportion of heterozygotes observed $\left(H_{0}\right)$ and allelic richness $(A$, number of alleles observed corrected across all samples for the minimum sample size screened). Genetic differentiation among samples was analysed using exact tests of differences in allele frequencies (using Genepop) and $F_{\mathrm{ST}}$ (Wright 1978).
Levels of $F_{\mathrm{ST}}$, estimated by $\theta$ (Weir \& Cockerham 1984) both globally and pairwise between samples, were calculated and tested for significant departure from zero (no differentiation) using permutation procedures within Fstat v. 2.9.3.2 (Goudet 1995). Where multiple tests were conducted, significance levels were adjusted according to a Bonferroni correction (Rice 1989).

In order to allow direct comparison of Doryteuthis pealeii results with those from Buresch et al. (2006), values of $F_{\text {IS }}$ within samples were generated from Fstat and all locus-by-sample combinations were tested for the presence of non-amplifying ('null') alleles using MicrocheCKer (van Oosterhout et al. 2004). Intersample differentiation $\left(F_{\mathrm{ST}}\right)$ was then recalculated and tested for significance (using Fstat) with the dataset corrected as indicated by MICROCHECKER to account for the presence of null alleles (using the Brookfield 1 algorithm, substituting a synthetic allele in place of 1 allele from selected 'false' homozygotes). Correction of datasets for null alleles can be important, as the presence of significant frequencies of null alleles has been shown to increase apparent differentiation between samples (Chapuis \& Estoup 2007). Both D. pealeii and Loligo reynaudii datasets were also tested for null alleles, and $F_{\text {ST }}$ values were recalculated and tested to account for null alleles, using FreeNA (Chapuis \& Estoup 2007, www.montpellier.inra.fr/URLB), to account for possible problems of using MicrocheCKER with this dataset (see 'Results' and 'Discussion').

\section{RESULTS}

\section{Genetic variability within samples}

A total of 387 individuals of Loligo reynaudii and 676 individuals of Doryteuthis pealeii were scored for 6 and 5 microsatellite loci, respectively. Genotype and allele frequency data are available from the corresponding author on request. Levels of genetic diversity within samples, in terms of number of alleles $(A)$ and observed heterozygosity $\left(H_{0}\right)$, were high and consistent among samples for both $L$. reynaudii $(A=18.0$ to 18.9, $H_{\mathrm{o}}=0.80$ to 0.87 ) and $D$. pealeii $(A=9.3$ to 10.1 , $H_{\mathrm{o}}=0.62$ to 0.74 ) - see Tables $2 \& 3$.

For Loligo reynaudii, 8 out of 90 tests displayed significant genotypic correlations in tests for linkage disequilibrium, although none remained significant after correction for multiple tests, and no locus pairs displayed significant linkage across all samples combined. As a result, all loci were considered to be independent. For Doryteuthis pealeii, 22 out of 90 tests displayed significant genotypic correlations, 6 remained significant after correction for multiple tests and no locus pairs displayed significant linkage across 
Table 2. Loligo reynaudii. Genetic variability at 6 microsatellite loci: sample size (n), allelic richness adjusted to minimum sample size of $34(A)$, observed heterozygosity $\left(H_{0}\right)$ and $F_{\mathrm{IS}}$ (significant deficit of heterozygotes: ${ }^{*} \mathrm{p}<0.05 ;{ }^{* *} \mathrm{p}<0.01$; values in bold remain significant after Bonferroni correction within loci). See Table 1 for sample designations

\begin{tabular}{|c|c|c|c|c|c|c|}
\hline & \multicolumn{6}{|c|}{ Sample code- } \\
\hline & $\mathrm{CT}$ & TS & SF03 & SF06 & $\mathrm{PE}$ & PA \\
\hline \multicolumn{7}{|c|}{ Lfor1 } \\
\hline$A$ & 20.7 & 22.8 & 21.0 & 17.9 & 19.2 & 17.8 \\
\hline$H_{\mathrm{o}}$ & 0.93 & 0.92 & 0.95 & 0.94 & 0.96 & 0.84 \\
\hline$F_{\mathrm{IS}}$ & 0.01 & 0.03 & -0.01 & -0.02 & -0.03 & $0.09^{*}$ \\
\hline \multicolumn{7}{|c|}{ Lfor3 } \\
\hline$A$ & 13.6 & 14.9 & 15.3 & 14.7 & 14.8 & 15.9 \\
\hline$H_{\mathrm{o}}$ & 0.89 & 0.81 & 0.87 & 0.93 & 0.97 & 0.90 \\
\hline$F_{\mathrm{IS}}$ & -0.04 & 0.05 & -0.01 & -0.06 & -0.08 & $0.02^{*}$ \\
\hline \multicolumn{7}{|c|}{ Lrey21 } \\
\hline$A$ & 14.5 & 13.5 & 13.7 & 12.6 & 12.9 & 14.2 \\
\hline$H_{\mathrm{o}}$ & 0.67 & 0.49 & 0.50 & 0.66 & 0.53 & 0.65 \\
\hline$F_{\mathrm{IS}}$ & $0.24^{* *}$ & $0.44^{* *}$ & $0.42^{* *}$ & $0.24^{* *}$ & $0.40^{* *}$ & $0.25^{* *}$ \\
\hline \multicolumn{7}{|c|}{ Lrey34 } \\
\hline$A$ & 18.5 & 17.7 & 17.5 & 18.2 & 18.0 & 17.7 \\
\hline$H_{\mathrm{o}}$ & 0.91 & 0.88 & 0.86 & 0.93 & 0.82 & 0.84 \\
\hline$F_{\mathrm{IS}}$ & 0.02 & 0.05 & 0.07 & 0.00 & $0.11^{*}$ & 0.08 \\
\hline \multicolumn{7}{|c|}{ Lrey44 } \\
\hline$A$ & 19.2 & 17.5 & 16.5 & 17.8 & 17.8 & 15.8 \\
\hline$H_{\mathrm{o}}$ & 0.96 & 0.82 & 0.71 & 0.90 & 0.83 & 0.83 \\
\hline$F_{\mathrm{IS}}$ & -0.02 & 0.10 & $0.22^{* *}$ & 0.03 & $0.10^{*}$ & $0.10^{*}$ \\
\hline \multicolumn{7}{|c|}{ Lrey48 } \\
\hline$A$ & 24.6 & 27.0 & 23.8 & 27.5 & 29.4 & 27.9 \\
\hline$H_{\mathrm{o}}$ & 0.87 & 0.88 & 0.89 & 0.86 & 0.91 & 0.88 \\
\hline$F_{\mathrm{IS}}$ & $0.09^{* *}$ & 0.08 & $0.07^{* *}$ & 0.11 & 0.06 & $0.09^{* *}$ \\
\hline \multicolumn{7}{|c|}{ Mean } \\
\hline$A$ & 18.5 & 18.9 & 18.0 & 18.1 & 18.7 & 18.2 \\
\hline$H_{\mathrm{o}}$ & 0.87 & 0.80 & 0.80 & 0.87 & 0.84 & 0.82 \\
\hline $\mathrm{n}$ & 48 & 60 & 80 & 67 & 48 & 84 \\
\hline
\end{tabular}

all samples combined: again, all loci were considered to be independent.

In tests for departure of genotype proportions from expectation under Hardy-Weinberg equilibrium ( $F_{\text {IS }}$ Table 2), for Loligo reynaudii, 15 out of 36 sample-bylocus tests were significant at $\mathrm{p}<0.05$, although only 6 remained significant after Bonferroni correction for multiple tests within loci. Of the 6 significant results, 5 were found at the same locus (Lrey21), all due to deficits of heterozygotes. Testing with MicrochECKER indicated the likely presence of a null allele within locus Lrey21, in 4 out of 6 samples at frequencies of from 3 to $9 \%$, but not consistently within any of the other 5 loci (1 test for Lrey34 at 5\%, 2 tests for Lrey44 at 5 to $8 \%, 1$ test for Lrey48 at 5\% - no sample was involved more than once). For Doryteuthis pealeii, 21 out of 45 sample-by-locus tests were significant at $\mathrm{p}<0.05$, although only 9 remained significant after correction for multiple tests (Table 3). Of the 9 significant results, 5 were found at the same locus (Lfor3); all were due to deficits of heterozygotes. Testing with MICROCHECKER indicated the likely presence of a null allele within locus Lfor3, in 7 out of 9 samples at frequencies of 2 to $14 \%$, but not consistently within any of the other 4 loci (2 tests for Lp2 at 1 to $9 \%, 3$ tests for Lp4 at 2 to $8 \%, 2$ tests for Lp5 at 1 to $6 \%, 1$ test for Lp12 at $16 \%$ - no sample was involved more than twice). As a single locus exhibited evidence of null alleles in both L. reynaudii (Lrey21) and D. pealeii (Lfor3), subsequent analyses for genetic differentiation among samples were conducted both with and without these loci to assess the potential effects of the null alleles.

\section{Genetic differentiation among samples}

For Loligo reynaudii, the temporal samples from St Francis Bay (SF03 and SF06) exhibited no significant differences in allele frequencies, either tested using exact tests (no individual loci significant, combined probability $=0.16$ ) or with permutation testing of between-sample diversity $\left(F_{\mathrm{ST}}=0.001, \mathrm{p}=0.56\right)$. Tests of genetic differentiation among the whole sample set indicated very low and non-significant levels of intersample diversity $\left(F_{\mathrm{ST}}=0.001, \mathrm{~ns}\right)$, although exact tests indicated overall significant differences in allele frequencies ( $p=0.0009)$, but not in genotype frequencies $(\mathrm{p}=0.070)$. Pairwise tests between individual samples (Table 4 ) again indicated very low values of $F_{\mathrm{ST}}$ (0 to 0.005). Only the CT sample showed significant differences from other samples (SF and PA), of which only 1 result (SF) remained significant after correction for multiple tests. There was some indication of increasing genetic difference $\left(F_{\mathrm{ST}}\right)$ between geographically more distant samples (Western Cape versus Eastern Cape), but no significant isolation-by-distance effect was indicated by Mantel tests. Exact tests confirmed the pattern exhibited by $F_{\mathrm{ST}}$ values, with sample PA showing significant results against $\mathrm{CT}$ and $\mathrm{TS}$; however, only the CT versus SF result remained significant after correction for multiple tests. Values of $F_{\mathrm{ST}}$ were not substantially altered, and the significance of tests was not changed by removing locus Lrey21 from calculations or by applying MICROCHECKER modification of genotypes. Application of the FreeNA adjustment for the presence of null alleles also had little effect on $F_{\mathrm{ST}}$ values (Table 4), but did affect the number of significant results: only the CT versus SF comparison was significant, but became non-significant after adjustment for multiple tests.

For Doryteuthis pealeii, tests of genetic differentiation among the whole sample set indicated very low and nonsignificant levels of inter-sample diversity $\left(F_{\mathrm{ST}}=0.001\right.$, $\mathrm{ns})$, but exact tests indicated overall significant differences in allele and genotype frequencies $(p=0.0004)$. 
Table 3. Doryteuthis pealeii. Genetic variability at 5 microsatellite loci: sample size (n), allelic richness adjusted to minimum sample size of $34(A)$, observed heterozygosity $\left(H_{\mathrm{o}}\right)$ and $F_{\mathrm{IS}}$ (significant deficit of heterozygotes: ${ }^{*} \mathrm{p}<0.05,{ }^{* *} \mathrm{p}<0.01$; values in bold remain significant after Bonferroni correction within loci). See Table 1 for sample designations

\begin{tabular}{|c|c|c|c|c|c|c|c|c|c|}
\hline & 1 & 2 & 3 & 4 & 5 & 6 & 7 & 8 & 9 \\
\hline \multicolumn{10}{|c|}{ Lfor3 } \\
\hline$A$ & 11.5 & 13.0 & 10.3 & 11.1 & 12.1 & 10.1 & 10.7 & 11.0 & 10.3 \\
\hline$H_{\mathrm{o}}$ & 0.88 & 0.67 & 0.71 & 0.58 & 0.84 & 0.65 & 0.63 & 0.60 & 0.73 \\
\hline$F_{\mathrm{IS}}$ & -0.02 & $0.22^{* *}$ & $0.17^{*}$ & $0.31^{* *}$ & $0.04^{* *}$ & $0.22^{* *}$ & $0.28^{* *}$ & $0.30^{* *}$ & $0.15^{*}$ \\
\hline \multicolumn{10}{|c|}{ Lp2 } \\
\hline$A$ & 8.9 & 9.9 & 8.7 & 8.7 & 7.9 & 6.9 & 8.0 & 8.7 & 9.4 \\
\hline$H_{\mathrm{o}}$ & 0.74 & 0.63 & 0.71 & 0.71 & 0.67 & 0.58 & 0.79 & 0.72 & 0.59 \\
\hline$F_{\mathrm{IS}}$ & -0.01 & $0.15^{*}$ & 0.09 & $0.03^{* *}$ & 0.07 & $0.21^{*}$ & -0.02 & $0.08^{* *}$ & 0.19 \\
\hline \multicolumn{10}{|c|}{ Lp4 } \\
\hline$A$ & 18.3 & 19.6 & 21.3 & 19.8 & 17.8 & 19.7 & 20.4 & 19.5 & 19.7 \\
\hline$H_{\mathrm{o}}$ & 0.87 & 0.78 & 0.97 & 0.89 & 0.79 & 0.83 & 0.89 & 0.92 & 0.94 \\
\hline$F_{\mathrm{IS}}$ & $0.07^{* *}$ & $0.17^{*}$ & -0.03 & 0.0 & $0.14^{* *}$ & $0.11^{*}$ & 0.05 & 0.01 & 0.01 \\
\hline \multicolumn{10}{|c|}{ Lp5 } \\
\hline$A$ & 5.4 & 5.0 & 5.0 & 5.0 & 5.3 & 5.4 & 4.8 & 5.0 & 5.0 \\
\hline$H_{\mathrm{o}}$ & 0.64 & 0.58 & 0.58 & 0.55 & 0.61 & 0.63 & 0.46 & 0.61 & 0.56 \\
\hline$F_{\mathrm{IS}}$ & -0.02 & 0.01 & $0.15^{*}$ & 0.08 & -0.07 & $0.02^{*}$ & 0.16 & 0.05 & 0.04 \\
\hline \multicolumn{10}{|c|}{ Lp12 } \\
\hline$A$ & 4.3 & 3.0 & 4.5 & 3.7 & 5.1 & 4.5 & 4.5 & 3.4 & 4.2 \\
\hline$H_{\mathrm{o}}$ & 0.59 & 0.68 & 0.53 & 0.51 & 0.61 & 0.49 & 0.48 & 0.44 & 0.29 \\
\hline$F_{\mathrm{IS}}$ & -0.08 & -0.31 & $0.04^{*}$ & 0.00 & -0.09 & 0.14 & $0.17^{*}$ & 0.18 & $0.47^{* *}$ \\
\hline \multicolumn{10}{|c|}{ Mean } \\
\hline$A$ & 9.7 & 10.1 & 10.0 & 9.7 & 9.6 & 9.3 & 9.7 & 9.5 & 9.7 \\
\hline$H_{\mathrm{o}}$ & 0.74 & 0.67 & 0.70 & 0.65 & 0.70 & 0.64 & 0.65 & 0.66 & 0.62 \\
\hline $\mathrm{n}$ & 76 & 40 & 80 & 80 & 80 & 80 & 80 & 80 & 80 \\
\hline
\end{tabular}

Table 4. Loligo reynaudii. Estimates of genetic differentiation ( $F_{\mathrm{ST}}$ above diagonal, exact test probability below diagonal) between samples. Two values for $F_{\mathrm{ST}}$ are given-upper value: original genotypic data; lower value: genotypic data adjusted using FreeNA (see 'Materials and methods - Genetic data analysis'). Tests for $F_{\mathrm{ST}}$ significantly greater than zero: ${ }^{*} \mathrm{p}<0.05,{ }^{* *} \mathrm{p}<0.01$; values in bold remain significant after Bonferroni correction for multiple tests $(p<0.005)$. See Table 1 and Fig. 1 for sample locations

\begin{tabular}{|lccccc|}
\hline & \multicolumn{5}{c}{ Sample code } \\
\cline { 3 - 6 } & CT & TS & SF06 & PE & PA \\
\hline CT & & $<0.001$ & $\mathbf{0 . 0 0 5}^{* *}$ & 0.002 & $0.003^{*}$ \\
TS & 0.050 & & 0.001 & -0.002 & 0.003 \\
& & & 0.001 & -0.002 & 0.003 \\
SF06 & $\mathbf{0 . 0 0 1}$ & 0.033 & & -0.002 & -0.001 \\
PE & 0.036 & 0.204 & 0.863 & & $<0.001$ \\
PA & 0.007 & 0.009 & 0.267 & 0.070 & \\
\hline
\end{tabular}

Results of pairwise tests between individual samples (Table 5) indicated very low values of $F_{\mathrm{ST}}(0$ to 0.006$)$, with 7 out of 36 tests significant ( 3 at $p<0.01$ ), although none remain significant when corrected for multiple tests $(p<0.0014)$. Exact tests between pairs of samples
(Table 5) indicated more significant results (15 of 36 tests, 7 at $p<0.01$ ), although only 1 comparison, Stn 3 versus Stn 5, remained significant after correction for multiple tests. There was no geographically-based, distance-based, or habitat-based pattern to the higher (and significant) values of $F_{\mathrm{ST}}$. In addition, the number of significant values of $F_{\text {ST }}$ among inshore samples (Stns 1 to 5, 3 of 10 tests) was not much greater than between inshore and offshore samples (4 of 20 tests), and there were no significant $F_{\mathrm{ST}}$ values among offshore samples (Stns 6 to 10). Global $F_{\mathrm{ST}}$ among inshore samples $\left(F_{\mathrm{ST}}=0.001\right.$, ns; range $=0.000$ to $0.004)$ was very similar to that amongst offshore samples $\left(F_{\mathrm{ST}}=0, \mathrm{~ns}_{\text {; }}\right.$ range $=$ 0.000 to 0.001 ). Similarly for exact tests, 4 significant results occurred among inshore; 3, among offshore; and 9, between inshore and offshore samples. Exclusion of locus Lfor3 had no noticeable effect on levels, significance, or patterns of $F_{\mathrm{ST}}$ or exact test results. When the dataset was corrected for the estimated presence of null alleles using FreeNA and the $F_{\mathrm{ST}}$ values were recalculated, only 3 comparisons ( 3 vs. 5, 4 vs. 9, 5 vs. 9) were significantly different from zero, and none remained so after correction for multiple tests (Table 5). However, when the dataset was corrected for null alleles using MiCROCHECKER, $18 F_{\text {ST }}$ values were increased over those for the uncorrected genotype data and 19 values were significantly different from zero, with 12 remaining significant after correction for multiple tests (Table 5). As with the uncorrected data, the significant $F_{\mathrm{ST}}$ results with MicROCHECKER displayed no obvious geographical pattern, although 3 samples (Stns 3, 6 and particularly 9) accounted for all of the highly significant results.

\section{DISCUSSION}

Our study results indicate that geographically localised spawning aggregations of Loligo reynaudii and Doryteuthis pealeii do not represent genetically distinct populations. Identification of whether or not heavily fished spawning aggregations of squid are distinct populations is an important consideration for fisheries management, especially in light of recent efforts to apply ecosystem-based management methods (Pikitch et al. 2004) and the importance of squid as both predator and prey. Large-scale harvest operations of fish have been demonstrated to cause genetic effects 
Table 5. Doryteuthis pealeii. Estimates of genetic differentiation $\left(F_{\mathrm{ST}}\right.$ above diagonal, exact test probability below diagonal) between inshore and offshore samples. Three values for $F_{\mathrm{ST}}$ are given - upper value: original genotypic data; middle value: genotypic data adjusted using FreeNA; lower value: genotypic data adjusted using MicrocheCKer (see 'Materials and methods - Genetic data analysis'). Tests for $F_{\mathrm{ST}}$ significantly greater than zero: ${ }^{*} p<0.05$, ${ }^{* *} p<0.01$; values in bold remain significant after Bonferroni correction for multiple tests $(p<0.0014)$. See Table 1 and Fig. 1 for sample locations

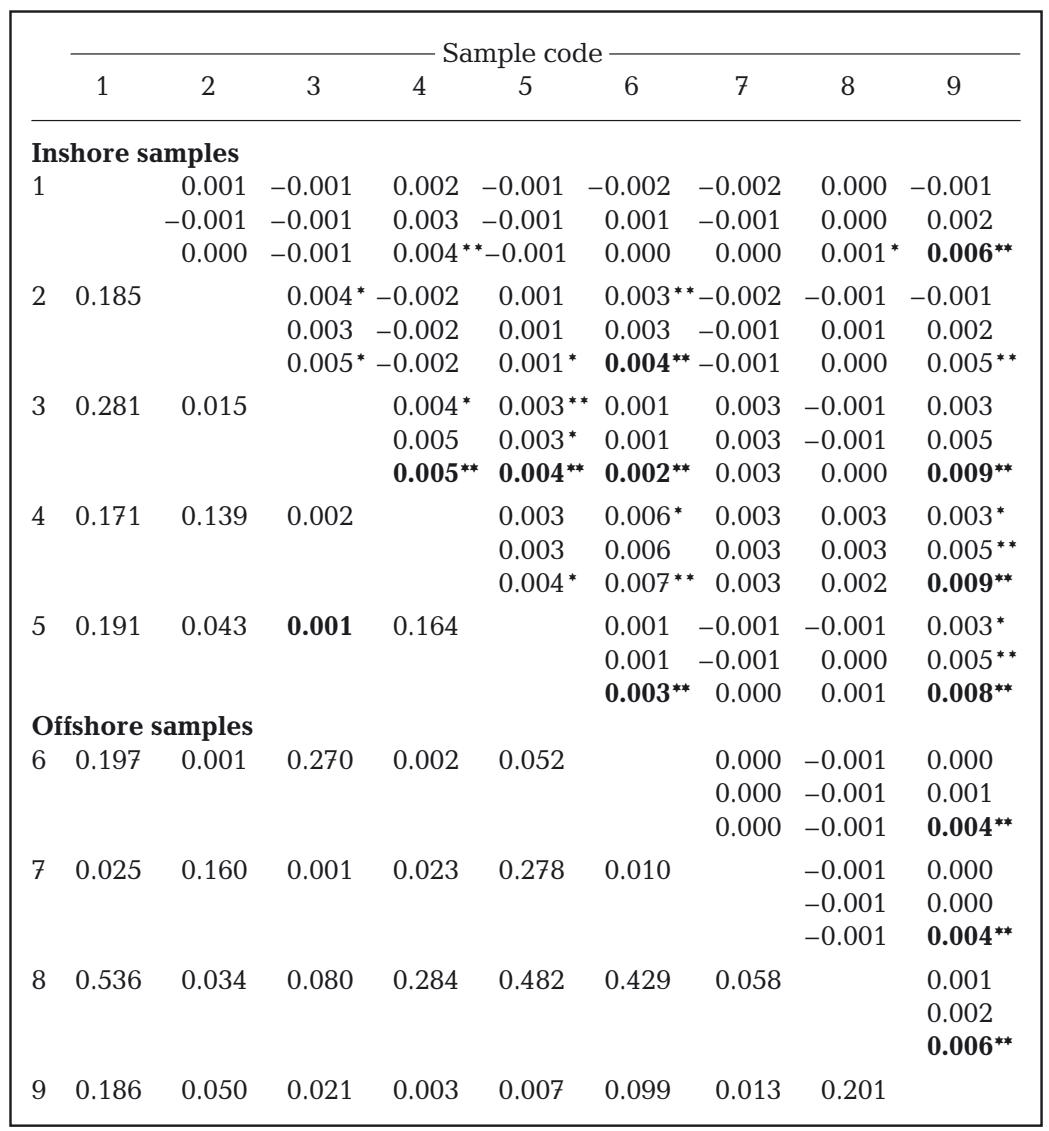

through selective removal of genotypes (Allendorf et al. 2008), and over-harvesting may result in extinction of local gene pools or reduce genetically effective population size (Ryman et al. 1981, Laikre \& Ryman 1996). Levels of genetic diversity detected in our investigation of nuclear microsatellite DNA loci within both $L$. reynaudii and $D$. pealeii were high and consistent across all samples; a pattern reported for most cephalopod species studied to date (Shaw 2002). As such, these data do not suggest that recent and extensive bottlenecks in population size have occurred, or that particular local populations have been more affected than others, on a genetic level, by fishing activities. The observed difference in diversity between the 2 species is likely due to the physical nature of the specific loci selected for use rather than true differences in underlying diversity, i.e. the loci for L. reynaudii were by chance more polymorphic than those used for $D$. pealeii.
Overall, the results for Loligo reynaudii indicate very little, if any, genetic differentiation of populations $\left(F_{\mathrm{ST}}=0\right.$ to 0.005 ) across most of the spawning range of this species, and they certainly give no support to the hypothesis that local spawning aggregations represent distinct genetic populations. Rather, the results support a hypothesis of effective mixing and interbreeding of $L$. reynaudii populations across substantial geographic areas, certainly across the multiple spawning aggregations occurring along the Eastern Cape coast. The results conform to expectations based on the dispersive life-history characteristics of the species (Augustyn et al. 1994), as well as to observations of long-distance migration of individuals among spawning aggregations (Sauer et al. 2000).

As with Loligo reynaudii, the results for Doryteuthis pealeii indicate very little, if any, genetic differentiation of populations ( $F_{\mathrm{ST}}=0$ to 0.006 ) across the geographical range sampled (>1000 km), and they give no support to the hypothesis that local spawning aggregations represent distinct genetic populations. Again, the results conform to expectations of large-scale mixing of populations resulting from dispersive life-history characteristics of the species (Jacobson 2005) and long-distance migration of individuals (Macy \& Brodziak 2001). Our results also agree with several previous molecular studies (Garthwaite et al. 1989, Herke \& Foltz 2002) that suggested genetic homogeneity across the area sampled in the present study, including areas further north and south of our sampling range (between 30 and $40^{\circ} \mathrm{N}$ ).

Our study results for Doryteuthis pealeii show a different picture to that presented by Buresch et al. (2006), who found significant genetic differences between all inshore spawning sites and between most inshore and offshore sites. Differences in the number of significant tests may have resulted from allele frequencies changing between the different years sampled during the 2 studies (i.e. winters of 2000 to 2002 vs. May 2006 to February 2007) and/or from increased instability of frequencies within the time sampled by Buresch et al. (2006). Squid populations display extreme fluctuations in recruitment success and abundance between different spawning cohorts and years (Boyle \& Rodhouse 2005), which has the potential to 
generate large and random fluctuations in gene frequencies, as well as short-term deficits of heterozygotes, resulting from biased reproductive success among individuals (Hedgecock 1994, Waples 1998). So differences in patterns revealed by the present study and the study by Buresch et al. (2006) may indicate temporal instability of gene frequencies, but the only conclusion that can be drawn regarding subpopulation differentiation is that any significant spatial patterns (as described by Buresch et al. 2006) are not temporally stable, and thus do not indicate temporally stable genetic spawning units.

Differences in the number of significant tests for Doryteuthis pealeii between the 2 studies may also have resulted from sample size differences between the 2 studies (an average of 48.4 individuals in Buresch et al. 2006 compared to an average of 75.1 individuals in the present study), or, may possibly have been due to an influence of the MicrocheCKER-adjusted data used by Buresch et al. (2006). In our study, when genotypic data for $D$. pealeii were adjusted using MicroCHECKER to account for the presence of significant frequencies of null alleles (as indicated by MicroCHECKER), increases in $\mathrm{F}_{\mathrm{ST}}$ values, as well as the number of significant tests, were observed, in comparison to the non-adjusted values. A clue to the source of these differences associated with the use of MicroCHECKER is that 10 of the 12 most significant $F_{\mathrm{ST}}$ tests from our study of $D$. pealeii involved just 2 stations (Stns 6 and 9), which, in both cases, were characterized by high and highly significant $F_{\mathrm{ST}}$ values at single loci (Lp2 at Stn 6 and Lp12 at Stn 9). These results were generated as a result of the substitution of relatively high frequencies (9 and 16\%, respectively) of the synthetic 'null' allele into the 2 loci that have small numbers (2 to 4 ) of common alleles. This effect of increased single-locus $F_{\mathrm{ST}}$ values was compounded by MicroCHECKER suggesting adjustment in only those locus/ sample combinations for which significant departures from Hardy-Weinberg equilibrium genotypic frequencies were indicated, even though many other locus/ sample combinations may have had low (but statistically non-significant) frequencies of null alleles indicated. Adjustment of allele frequencies using MicroCHECKER, therefore, may result in sample-specific alterations of allele frequencies, which, in turn, affects resulting tests for differentiation against other nonadjusted samples. Our study showed that these adjustments can have substantial consequences within loci displaying low numbers of common alleles. By contrast, application of the FreeNA method of adjusting for the presumed presence of null alleles produces results almost identical to the non-adjusted data. FreeNA estimates the frequency of null alleles and adjusts frequencies of visible alleles accordingly, but then recalculates $F_{\mathrm{ST}}$ using frequencies of visible alleles only (Chapuis \& Estoup 2007) and so does not generate high frequencies of a synthetic allele within loci with few visible alleles. FreeNA also estimates frequencies of null alleles and carries out the corresponding adjustment, at all loci in all samples, and so applies a uniform adjustment that does not create potential for sample-specific bias at low-polymorphism loci. Where all loci screened display many alleles at low to medium frequencies, as for the Loligo reynaudii dataset (22 to 39 alleles per locus), Microchecker and FreeNA generate very similar results; in the case of L. reynaudii, this did not substantially change values or significance of $F_{\mathrm{ST}}$ as would be expected where no significant differentiation exists (Chapuis \& Estoup 2007). It is clear from the example of the $D$. pealeii dataset that application of adjustments to genotypic data should be made with great care, particularly where individual loci display few and/or very common alleles.

We conclude that discrete spawning aggregations of Loligo reynaudii and Doryteuthis pealeii do not represent genetically distinct subpopulations. Although it is possible that isolated subpopulations may exist but that insufficient time has elapsed to allow significant genetic drift to accumulate in species with large census population sizes, evidence from other studies suggests that this possibility is unlikely. Tagging studies indicate movement of individuals between spawning sites (Sauer et al. 2000), and extreme census size fluctuations observed for squid populations (Boyle \& Boletzky 1996) would be predicted to quickly generate genetic drift; both observations support an interpretation that the absence of genetic differences reflect non-isolated spawning aggregations. With respect to L. reynaudii, our detection of slight genetic differentiation between the Western Cape and Eastern Cape samples may support recent observations of morphological differences between squid from these 2 areas (T. Stonier \& M. Lipinski unpubl. data). Such subtle genetic differentiation of geographically peripheral subpopulations has been noted in other squid species (e.g. Shaw et al. 1999) and may be related to retention of paralarvae within largescale current systems.

Similar to our study results, a lack of genetic differentiation between populations has been indicated for other loliginid squid species, such as Loligo opalescens (Reichow \& Smith 2001) and Loligo gahi (Shaw et al. 2004), suggesting that lack of genetic structuring may be common for highly mobile, neritic squid species that produce benthic egg masses attached to substrates. However, large-scale genetic homogeneity, indicating high levels of interbreeding and gene flow, cannot always be assumed for cephalopods. For example, in several species of cuttlefish, which are highly mobile as adults but less mobile at the benthic paralarval 
stage, continuously distributed populations display significant genetic structuring, which fits the expectations of an isolation-by-distance model of restricted gene flow (Perez Losada et al. 2002, Kassahn et al. 2003). Nevertheless, our results extend the picture of squid species displaying genetically homogeneous populations over large geographical scales, unless specific oceanographic features create a barrier to gene flow (e.g. Shaw et al. 1999, Triantafillos \& Adams 2001, Herke \& Foltz 2002, Shaw et al. 2004).

Acknowledgements. We greatly appreciate the sampling efforts of L. Brady, P. Chase, D. Byrne, K. Gottschall, J. King, C. Pickett and P. Politis (Doryteuthis pealeii), and the crews of the RV 'Nansen' and commercial fishing vessels for access to their catches (Loligo reynaudii). We also thank K. Martin for allowing L. Hendrickson to participate in the harvesting of D. pealeii and to obtain squid samples from his weirs. We are grateful to M.-P. Chapuis and C. van Oosterhout for helpful discussions regarding the use of FreeNA and MiCROCHECKER programmes for testing and adjusting datasets for the presence of null alleles. We are grateful to S. Stiles for comments on an early version of the manuscript.

\section{LITERATURE CITED}

Adcock GJ, Shaw PW, Rodhouse PG, Carvalho GR (1999) Microsatellite analysis of genetic diversity in the squid Illex argentinus during a period of intensive fishing. Mar Ecol Prog Ser 187:171-178

Allendorf FW, England PR, Luikart G, Ritchie PA, Ryman N (2008) Genetic effects of harvest on wild animal populations. Trends Ecol Evol 23:327-337

Augustyn CJ, Lipinski MR, Sauer WHH (1992) Can the Loligo squid fishery be managed effectively? A synthesis of research on Loligo vulgaris reynaudii. In: Payne AIL, Brink KH, Mann KH, Hilborn R (eds) Benguela trophic functioning. S Afr J Mar Sci 12:903-918

Augustyn CJ, Lipinski MR, Sauer WHH, Roberts MJ, Mitchell-Innes BA (1994) Chokka squid on the Agulhas Bank: life history and ecology. S Afr J Mar Sci 12:143-154

Avise JC (2004) Molecular markers, natural history and evolution. Sinauer Associates Publishers, Sunderland, MA

Azarovitz T (1981) A brief historical review of the Woods Hole Laboratory trawl survey time series. In: Doubleday WG, Rivard D (eds) Bottom trawl surveys. Can Spec Publ Fish Aquat Sci 58:62-67

Bekkevold D, Andre C, Dahlgren TG, Clausen LAW and others (2005) Environmental correlates of population differentiation in Atlantic herring. Evolution 59:2656-2668

Boyle PR, Boletzky SV (1996) Cephalopod populations: definitions and dynamics. Philos Trans R Soc Lond B 351: 985-1002

Boyle PR, Rodhouse P (2005) Cephalopods: ecology and fisheries. Blackwell, London

Brodziak J, Hendrickson L (1999) An analysis of environmental effects on survey catches of squids Loglio paelei and Illex illecebrosus in the northwest Atlantic. Fish Bull 97: 9-24

Brodziak JKT, Macy WK III (1996) Growth of long-finned squid, Loligo pealei, in the northwest Atlantic. Fish Bull 94:212-236
Buresch KC, Gerlach G, Hanlon RT (2006) Multiple genetic stocks of longfin squid Loligo pealeii in the NW Atlantic: stocks segregate inshore in summer, but aggregate offshore in winter. Mar Ecol Prog Ser 310:263-270

Carvalho GR, Thomson A, Stoner AL (1992) Genetic diversity and population differentiation of the shortfin squid Illex argentinus in the south-west Atlantic. J Exp Mar Biol Ecol 158:105-121

Chapuis MP, Estoup A (2007) Microsatellite null alleles and estimation of population differentiation. Mol Biol Evol 24: $621-631$

Cimmaruta R, Bondanelli P, Ruggi A, Nascetti G (2008) Genetic structure and temporal stability in the horse mackerel (Trachurus trachurus). Fish Res 89:114-121

> Dawe EG, Hendrickson LC, Colbourne EB, Drinkwater KF, Showell MA (2007) Ocean climate effects on the relative abundance of short-finned squid (Illex illecebrosus) and long-finned squid (Loligo pealeii) in the northwest Atlantic Ocean. Fish Oceanogr 16:303-316

Dillane E, Galvin P, Coughlan J, Lipinski M, Cross TF (2005) Genetic variation in the lesser flying squid Todaropsis eblanae (Cephalopoda, Ommastephidae) in east Atlantic and Mediterranean waters. Mar Ecol Prog Ser 292: $225-232$

Garthwaite RL, Berg CJ, Harrigan J (1989) Population genetics of the common squid Loligo pealei LeSueur, 1821, from Cape Cod to Cape Hatteras. Biol Bull 177:287-294

Goudet J (1995) Fstat (version 1.2): a computer program to calculate F-statistics. J Hered 86:485-486

Hatfield EMC, Cadrin SX (2002) Geographic and temporal patterns in size and maturity of the longfin inshore squid (Loligo pealeii) off the northeastern United States. Fish Bull 100:200-213

Hedgecock D (1994) Does variance in reproductive success limit effective population size of marine organisms? In: Beaumont A (ed) Genetics and evolution of aquatic organisms. Chapman \& Hall, London, p 122-134

$>$ Herke SW, Foltz DW (2002) Phylogeography of two squid (Loligo pealei and L. plei) in the Gulf of Mexico and northwestern Atlantic Ocean. Mar Biol 140:103-115

Jacobson LD (2005) Essential fish habitat source document: longfin inshore squid, Loligo pealeii, life history and habitat characteristics, 2nd edn. NOAA Tech Memo NMFSNE-193

> Kassahn KS, Donellan SC, Fowler T, Hall KC, Adams M, Shaw PW (2003) Molecular and morphological analyses of the cuttlefish Sepia apama indicate a complex population structure. Mar Biol 143:947-962

Laikre L, Ryman N (1996) Effects on intraspecific biodiversity from harvesting and enhancing natural populations. Ambio 25:504-509

> Macy WK III, Brodziak JKT (2001) Seasonal maturity and size at age of Loligo pealeii in waters of southern New England. ICES J Mar Sci 58:852-864

> Mariani S, Hutchinson WF, Hatfield EMC, Ruzzante DE and others (2005) North Sea herring population structure revealed by microsatellite analysis. Mar Ecol Prog Ser 303: $245-257$

> Martínez P, Pérez Lozada M, Guerra EA, Sanjuan EA (2005) First genetic validation and diagnosis of the short-finned squid species of the genus Illex (Cephalopoda: Ommastrephidae). Mar Biol 148:97-108

> Maxwell MR, Buresch KM, Hanlon RT (2000) Pattern of inheritance of microsatellite loci in the squid Loligo pealeii (Mollusca: Cephalopoda). Mar Biotechnol 2:517-521

> Melo Y, Sauer WHH (1999) Confirmation of serial spawning in the chokka squid (Loligo vulgaris reynaudii). Mar Biol 
135:307-313

Naud MJ, Shaw PW (2008) Isolation and characterization of highly polymorphic microsatellites in the chokka squid, Loligo reynaudii. Mol Ecol Res 8:943-945

Nesbø CL, Rueness EK, Iversen SA, Skagen DW, Jakobsen KS (2000) Phylogeography and population history of Atlantic mackerel (Scomber scombrus L.): a genealogical approach reveals genetic structuring among the eastern Atlantic stocks. Proc Biol Sci 267:281-292

Olyott LJH, Sauer WHH, Booth AJ (2007) Spatial patterns in the biology of the chokka squid, Loligo reynaudii on the Agulhas Bank, South Africa. Rev Fish Biol Fish 17: 159-172

Palumbi SR (2004) Marine reserves and ocean neighbourhoods: the spatial scale of marine populations and their management. Annu Rev Environ Resour 29:31-68

Perez Losada M, Guerra A, Carvalho GR, Sanjuan A, Shaw PW (2002) Fine population structuring of the cuttlefish Sepia officinalis (Mollusca: Cephalopoda) around the Iberian peninsula revealed by microsatellite DNA markers. Heredity 89:417-424

Pikitch EK, Santora C, Babcock EA, Bakun A and others (2004) Ecosystem-based fishery management. Science 305:346-347

Raymond M, Rousset F (1995) GENEPOP (Version 1.2): population genetics software for exact tests and ecumenicism. J Hered 86:248-249

Reichow D, Smith MJ (2001) Microsatellites reveal high levels of gene flow among populations of the California squid Loligo opalescens. Mol Ecol 10:1101-1110

Rice WR (1989) Analyzing tables of statistical significance. Evolution 43:223-225

Rodhouse PG, Dawe EG, O'Dor RK (1998) Squid recruitment dynamics: the genus Illex as a model, the commercial Illex species and influences on variability. FAO Fish Tech Pap 376

Roper CFE, Sweeney MJ, Nauen CE (1984) FAO species catalogue, Vol 3. Cephalopods of the world: an annotated and illustrated catalogue of species of interest to fisheries. FAO Fish Synop 3

Ruzzante DE, Taggart CT, Doyle RW, Cook D (2001) Stability in the historical pattern of genetic structure of Newfoundland cod (Gadus morhua) despite the catastrophic decline in population size from 1964 to 1994 . Conserv Genet 2: 257-269

Ryman N, Baccus R, Reuterwall C, Smith MH (1981) Effective population size, generation interval, and potential loss of genetic variability in game species under different hunting regimes. Oikos 36:257-266

Sauer WHH, Smale MJ, Lipinski MR (1992) The location of spawning grounds, spawning and schooling behaviour of the squid Loligo vulgaris reynaudii (d'Orbigny) (Cephalopoda: Myopsida) off the eastern Cape coast. Mar Biol 114: 97-107

Sauer WHH, Lipinski MR, Augustyn CJ (2000) Tag recapture

Editorial responsibility: Hans Heinrich Janssen, Oldendorf/Luhe, Germany studies of the chokka squid Loligo vulgaris reynaudii d'Orbigny, 1845 on inshore spawning grounds on the south-east coast of South Africa. Fish Res 45:283-289

> Shaw PW (1997) Polymorphic microsatellite markers in a cephalopod: the veined squid Loligo forbesi. Mol Ecol 6: 297-298

Shaw PW (2002) Past, present and future applications of DNA-based markers in cephalopod biology. Bull Mar Sci 71:67-78

Shaw PW, Pierce G, Boyle PR (1999) Subtle population structuring within a highly vagile marine invertebrate, the veined squid Loligo forbesi, demonstrated with microsatellite DNA markers. Mol Ecol 8:407-417

Shaw PW, Arkhipkin AI, Adcock GJ, Burnett WJ, Carvalho GR, Scherbich JN, Villegas PA (2004) DNA markers indicate that distinct spawning cohorts and aggregations of Patagonian squid, Loglio gahi, do not represent genetically discrete subpopulations. Mar Biol 144:961-970

Sotelo G, Moran P, Luis Fernández L, Posada D (2008) Genetic variation of the spiny spider crab Maja brachydactyla in the northeastern Atlantic. Mar Ecol Prog Ser 362:211-223

Summers WC (1983) Loligo pealei. In: Boyle PR (ed) Cephalopod life cycles, Vol 1. Species accounts. Academic Press, London, p 115-142

Triantafillos L, Adams M (2001) Allozyme analysis reveals a complex population structure in the southern calamari Sepioteuthis australis from Australia and New Zealand. Mar Ecol Prog Ser 212:193-209

Triantafillos L, Jackson GD, Adams M, McGrath-Steer B (2004) An allozyme investigation of the stock structure of arrow squid Nototodarus gouldi (Cephalopoda: Ommastrephidae) from Australia. ICES J Mar Sci 61:829-835

Triantafyllidis A, Apostolidis AP, Katsares V, Kelly E and others (2005) Mitochondrial DNA variation in the European lobster (Homarus gammarus) throughout the range. Mar Biol 146:223-235

van Oosterhout C, Hutchinson WF, Derek PMW, Shipley P (2004) MICRO-CHECKER: software for identifying and correcting genotyping errors in microsatellite data. Mol Ecol Notes 4:535-538

Vecchione M, Shea E, Bussarawit S, Anderson F and others (2005) Systematics of Indo-West Pacific loliginids. Res Bull Phuket Mar Biol Cent 66:23-26

Waples RS (1998) Separating the wheat from the chaff: patterns of genetic differentiation in high gene flow species. J Hered 89:438-450

Weir BS, Cockerham CC (1984) Estimating F-statistics for the analysis of population structure. Evolution 38:1358-1370

Winnepenninckx B, Backeljau T, Dewachter R (1993) Extraction of high molecular-weight DNA from molluscs. Trends Genet 9:407

Wright S (1978) Evolution and the genetics of populations, Vol 4. University of Chicago Press, Chicago, IL

> Yeatman J, Benzie JAH (1994) Genetic structure and distribution of Photololigo in Australia. Mar Biol 118:79-87

Submitted: September 22, 2009; Accepted: March 17, 2010

Proofs received from author(s): May 11, 2010 